\title{
Approach to Paroxysmal Atrial Fibrillation Type Arrhythmia in a Cardiology Service: A Case Report
}

\author{
Miriam Viviane Baron 1,2*, Luis Manuel Ley Dominguez³, Carolina Paz Mohamad Isa3, \\ Gabriela Di Lorenzo Garcia Scherer ${ }^{3}$, Michele Paula dos Santos ${ }^{3}$, \\ Vitória Pereira Itaquy ${ }^{4}$, Talia Guimarães dos Santos ${ }^{4}$, \\ Julia Braga da Silveira4, Paulo Ricardo Martins ${ }^{3}$, \\ Amanda Corrêa dos Santos ${ }^{3}$, Marcus Vinicius de Mello Pinto5, \\ Janine Koepp ${ }^{6}$, Daiana Klein Weber Carissimi ${ }^{6}$, Joice Nedel Ott ${ }^{1}$, \\ Carolina Gonçalves Pinheiro ${ }^{7,8}$, Nathália Ken Pereira Iketani9, \\ Gabriela Feltez ${ }^{10}$, Bartira Ercília Pinheiro da Costa ${ }^{11}$
}

\footnotetext{
${ }^{1}$ Postgraduate Program in Medicine and Health Sciences of the Pontifical Catholic University of Rio Grande do Sul (PUC/RS), Porto Alegre, Brazil

${ }^{2}$ Improvement of Higher Education Personnel, Brazil (CAPES), Distrito Federal, Brazil

${ }^{3}$ School of Medicine of the Pontifical Catholic University of Rio Grande do Sul (PUC/RS), Porto Alegre, Brazil

${ }^{4}$ School of Health and Life Sciences of the Pontifical Catholic University of Rio Grande do Sul (PUC/RS), Porto Alegre, Brazil

${ }^{5}$ Celulare Institute, Petrópolis, Brazil

${ }^{6}$ Undergraduate Nursing Course of the University of Santa Cruz do Sul (UNISC), Santa Cruz do Sul, Brazil

${ }^{7}$ Postgraduate Program in Health Sciences of the Faculty of Medicine of ABC (FMABC), São Paulo, Brazil

${ }^{8}$ Undergraduate Physiotherapy Course of the Vale do Salgado Faculty (FVS), Ceará, Brazil

${ }^{9}$ Physiotherapy of the Hospital Beneficiente Portuguesa of Belém, Pará, Brazil

${ }^{10}$ Rehabilitation Sciences of the Federal University of Health Sciences of Porto Alegre, Porto Alegre, Brazil

${ }^{11}$ Postgraduate Program in Medicine and Health Sciences, School of Medicine of the Pontifical Catholic University of Rio Grande do Sul (PUC/RS), Porto Alegre, Brazil

Email: *miriambaron9@gmail.com
}

How to cite this paper: Baron, M.V., Dominguez, L.M.L., Isa, C.P.M., Scherer, G.D.L.G., dos Santos, M.P., Itaquy, V.P., dos Santos, T.G., da Silveira, J.B., Martins, P.R., dos Santos, A.C., de Mello Pinto, M.V., Koepp, J., Carissimi, D.K.W., Ott, J.N., Pinheiro, C.G., Iketani, N.K.P., Feltez, G. and da Costa, B.E.P. (2020) Approach to Paroxysmal Atrial Fibrillation Type Arrhythmia in a Cardiology Service: A Case Report. Modern Research in Inflammation, 9, 9-17.

https://doi.org/10.4236/mri.2020.92002

\begin{abstract}
Atrial fibrillation is a cardiac arrhythmia of high prevalence in the population, especially in the elderly. Its main electrical characteristics are the interval between two successive irregular $\mathrm{R}$ waves, absence of $\mathrm{P}$ waves and presence of $f$ waves between QRS complexes. The most common symptoms of atrial fibrillation are irregular palpitations associated with dyspnea, dizziness, feeling tired, fatigue and general malaise, but not all patients have any symptoms. The present report presents the history of an elderly patient who arrived at the hospital's emergency department with irregular heart rhythm and palpitations. The patient's symptoms, associated with the electrocardiogram
\end{abstract}


Received: March 31, 2020

Accepted: May 4, 2020

Published: May 7, 2020

Copyright $\odot 2020$ by author(s) and Scientific Research Publishing Inc. This work is licensed under the Creative Commons Attribution International License (CC BY 4.0).

http://creativecommons.org/licenses/by/4.0/ results, indicated paroxysmal atrial fibrillation. Electrical cardioversion was performed, and after, cardiac ablation via the femoral vein at the hospital's cardiology service. There were no complications during the procedure. As a routine imaging exam after ablation, control esophagogastroduodenoscopy was requested to verify that there was no formation of atrio-esophageal fistula developed by the invasive ablation procedure and electrocardiogram, which showed normal sinus rhythm. The patient remained in the cardiac intensive care unit for observation for 24 hours. After the electrical cardioversion and catheter ablation procedures, the patient improved his clinical picture of atrial fibrillation and was discharged after 24 hours of hospitalization. He received treatment to perform at home, to reduce acid reflux into the esophagus and to prevent thrombosis. He did not present pulmonary thromboembolism after hospital discharge. It is believed, therefore, that this form of treatment and management of paroxysmal atrial fibrillation is effective for the solution of the proposed problem and can also serve as a reference for other professionals within the cardiology service.

\section{Keywords}

Atrial Fibrillation, Electrical Cardioversion, Catheter Ablation, Hypertension, Obstructive Sleep Apnea Syndrome

\section{Introduction}

Atrial fibrillation (AF) is a highly prevalent cardiac arrhythmia in the population-especially in the elderly [1]. The AF lasts, on average, more than 30 seconds and its main electrical characteristics are the interval between two successive irregular $R$ waves, absence of $P$ waves and presence of $f$ waves between QRS complexes. It presents irregular $\mathrm{f}$ waves in morphology and time and baseline undulations at frequencies above $300 \mathrm{bpm}$ - generally more visible in lead V1 [2].

Paroxysmal or intermittent AF, in turn, is one of the forms of presentation of $\mathrm{AF}$, which is defined as episodes of palpitations that end spontaneously or with interventions in less than seven days [3]. AF occurs in about $4 \%$ of patients over the age of 60 [4]. However, the frequency of paroxysmal AF is undetermined, in addition to the fact that most patients are asymptomatic [5]. It is estimated that, in Brazil, there are around 1.5 million people with AF, and that this population is directly related to the age pyramid, that is, in addition to the prevalence of the disease increasing with age, more than $95 \%$ of patients with AF are 60 years or older [6].

In other countries, such as Sweden, the rate of patients with AF is similar to the Brazilian one. A retrospective study of patients with a clinical diagnosis of AF, between 2005 and 2010, in the Swedish National Registry, approaches 3\% of the Swedish adult population. In the United States (US) and Australia, numbers 
show that, in patients over 40 years, one in 4 adults will develop AF throughout their lives-in addition to that, the official data from the US most likely underestimate the extent of the issue by a factor of approximately 5 [7].

The most common symptoms of AF are irregular palpitations associated with dyspnea, dizziness, feeling tired, fatigue and general malaise, but not all patients have any symptoms [8]. AF is also more common in men than in women and is more common in whites than in blacks [9]. Some of the factors that trigger episodes of AF are the practice of moderate or intense physical activity, elitism and emotional disorders [10].

The present report presents the history of an elderly patient diagnosed with paroxysmal AF and the need for cardioversion, seen in the emergency department (ED) of the hospital and later transferred to the intensive care unit (ICU) cardiovascular. The patient was recruited and accepted to participate in research carried out in the ICU with CAEE number: 91988318.6.0000.5336-Brazil. The case is reported here for sharing with colleagues.

\section{Case Report}

A white, 60-year-old male patient arrived at the hospital's ED on 01/15/20 with symptoms of palpitations and irregular heart rhythm. He reported that, at home, he had been presenting a clinical picture of irregular palpitations accompanied by dyspnea on exertion, dizziness and confusion, but was unable to specify how long these symptoms started. The patient had comorbidities such as systemic arterial hypertension (SAH), diabetes mellitus (DM), dyslipidemia and obstructive sleep apnea/hypopnea syndrome (OSAHS).

He presented, in terms of previous medical history, two electrical cardioversions in episodes of symptomatic AF approximately three years before his treatment at the ED-on 08/11/2016 and on 09/08/2016-multiple episodes of cholelithiasis and angiolipoma in right kidney. In addition, he reported having been a smoker for many years-a time that was undetermined by the patient. At home, he used Losartan ${ }^{\circledR}$ (losartan potassium) $50 \mathrm{mg}$, Anlodipino ${ }^{\circledR}$ (amlodipine besylate) $5 \mathrm{mg}$, Xarelto ${ }^{\oplus}$ (rivaroxaban) $20 \mathrm{mg}$, Selozok ${ }^{\oplus}$ (metoprolol succinate $50 \mathrm{mg}$ ), Ancoron ${ }^{\circledast}$ (amiodarone hydrochloride) $200 \mathrm{mg}$, Rusovas ${ }^{\circledast}$ (rosuvas-

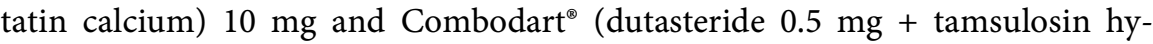
drochloride $0.4 \mathrm{mg}$ ).

Upon admission, the patient had a blood pressure (BP) of $155 / 84 \mathrm{mmHg}$, heart rate (HR) of $83 \mathrm{bpm}$, oxygen saturation $\left(\mathrm{SpO}_{2}\right)$ of $99 \%$ and hemoglycotest (HGT) of $95 \mathrm{mg} / \mathrm{dL}$. On physical examination, his abdomen had positive hydro-air noises and was flaccid, helpless and innocent. The electrocardiogram (ECG) showed sinus rhythm accompanied by left atrial overload, as shown in Figure 1 below. ECG also found absence of $\mathrm{P}$ waves and presence of $\mathrm{f}$ waves between QR complexes.

The patient's symptoms, associated with the ECG results, therefore indicated paroxysmal AF. The other aspects were normal. That same day, 150J electrical 

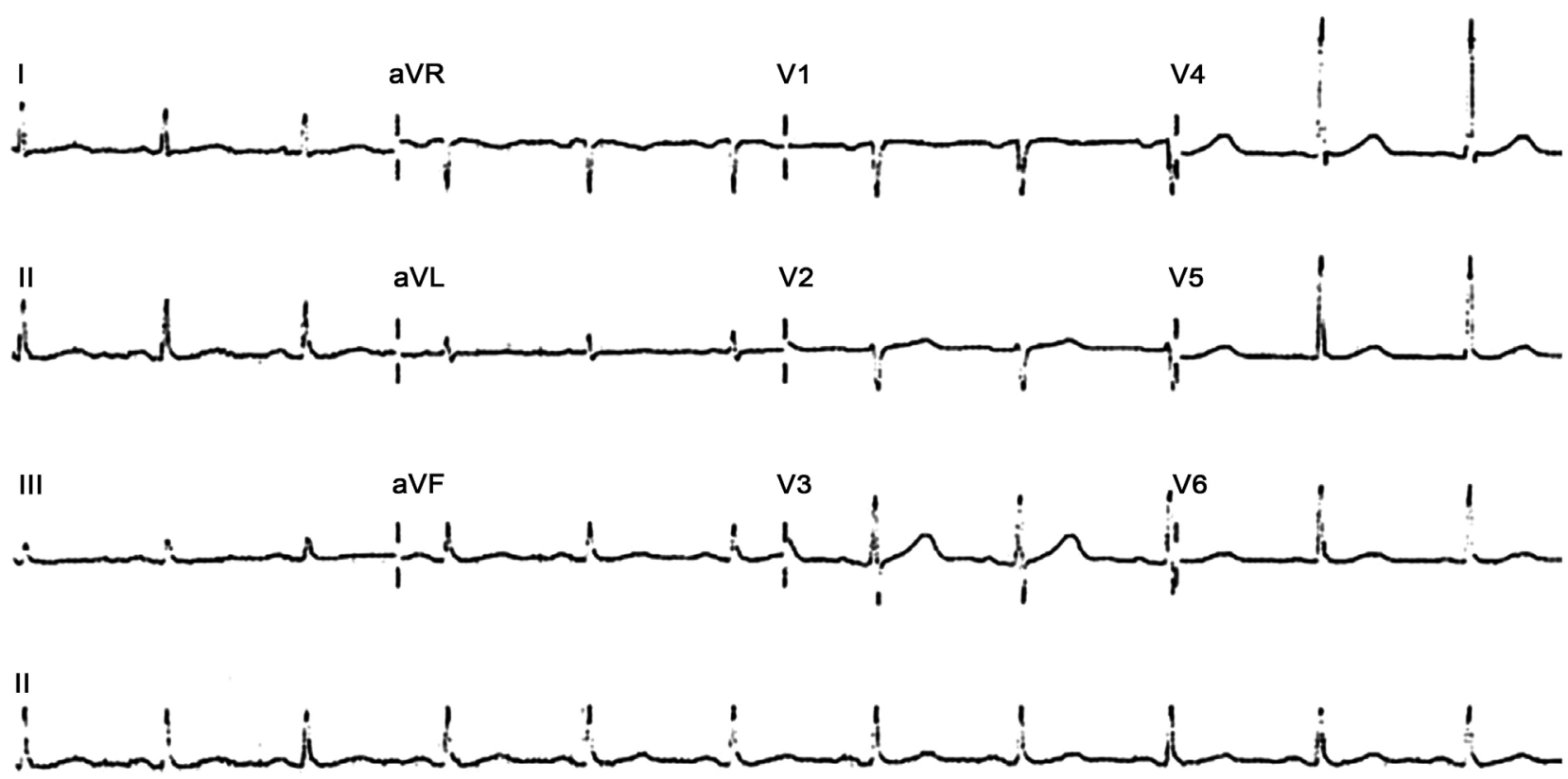

Figure 1. ECG with sinus rhythm accompanied by left atrial overload. Source: Author data.

cardioversion was performed without complications. After the cardioversion procedure, the patient was referred to the cardiac ablation procedure via the femoral vein at the hospital's cardiology service. Ablation was performed by performing two punctures of the right femoral vein and two punctures of the left femoral vein. Soon after, radiofrequency applications were performed, with the creation of a circumferential line around the left pulmonary vein ostium (single ostium) and the right pulmonary vein. There were no complications during the procedure.

As a routine imaging exam after ablation, control esophagogastroduodenoscopy was requested to verify that there was no formation of atrio-esophageal fistula developed by the invasive ablation procedure, since the posterior wall of the left atrium maintains an intimate anatomical relationship with the wall anterior esophagus-consequently, the displacement of the ablation lines of the pulmonary vein ostia to the posterior wall of the left atrium brings the isolation lines towards the esophagus, whose wall may suffer thermal injury by proximity. The ECG after the ablation showed sinus rhythm within the normal range as shown in Figure 2 below.

After the ablation and esophagogastroduodenoscopy procedures, the patient remained in the cardiac ICU for recovery and observation for 24 hours. During this period, he received medications such as Eliquis ${ }^{\circledast}$ (apixaban) $5 \mathrm{mg}$, Selozok ${ }^{\circledR}$ $50 \mathrm{mg}$, Losartan ${ }^{\oplus} 50 \mathrm{mg}$, Anlodipino 5 mg, Ancoron ${ }^{\circledR} 200 \mathrm{mg}$ and Rusovas ${ }^{\circledR} 10$ mg.

While hospitalized for recovery, imaging and laboratory tests were also requested. Results of laboratory tests—blood count: erythrocytes 4.66 million/ $\mu \mathrm{L}$, hematocrit $42.6 \%$, hemoglobin $14.5 \mathrm{~g} / \mathrm{dL}$, leukocytes $6.870 / \mu \mathrm{L}$, platelets $187.000 / \mu \mathrm{L}$, sodium $141 \mathrm{mEq} / \mathrm{L}$, potassium $4.5 \mathrm{mEq} / \mathrm{L}$, urea $33 \mathrm{mg} / \mathrm{dL}$ and creatinine 1.00 

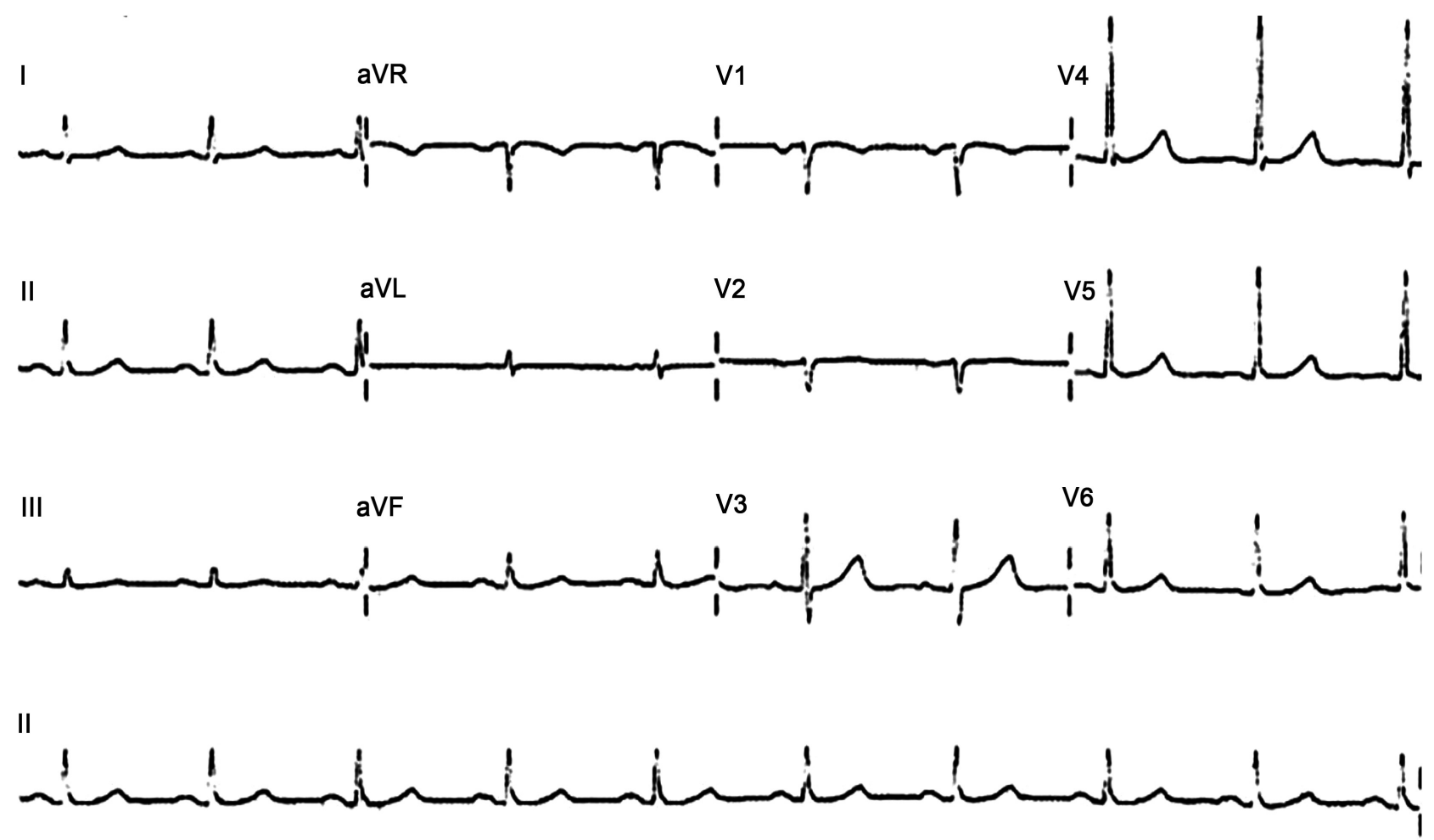

Figure 2. ECG with sinus rhythm and other aspects within the normal range. Source: Author data.

$\mathrm{mg} / \mathrm{dL}$. Control image examination (esophagogastroduodenoscopy) after ablation showed normal-looking esophageal mucosa and $\mathrm{Z}$ line at the level of diaphragmatic clamping. The stomach was shown with a fornix mucosa and a normal-looking body. In the great curvature of the stomach antrum, there was a sessile polyp $5 \mathrm{~mm}$ in diameter. Symmetrical and permeable pylorus. Duodenum presented a normal-looking bulb and second duodenal portion.

During the 24 hours of recovery, after the procedure, the patient evolved with symptom improvement and denied chest pain, dyspnea and dysphagia. Vital signs were stable with BP 120/70 mmHg, HR 58 bpm and FR 17 irpm. In monitoring, the ECG remained with sinus rhythm and other aspects within the normal range. The patient was admitted on 1/15/2020 for the procedure and was discharged from the cardiac ICU on $1 / 16 / 2020$. He received treatment to perform at home with rivaroxabana $5 \mathrm{mg}$, as a thrombosis prevention.

\section{Discussion}

In the present report, it is possible to observe that the patient had several comorbidities such as SAH, OSAHS and dyslipidemia, in addition to the fact that he was 60 years old. All of these, together, are contributing factors for the development of paroxysmal AF [11]. AF is associated with an increase in morbidity and mortality and the risk of developing heart failure, in addition to an increased incidence in patients over 60 years of age [12]. In addition, several studies have emphasized the role of OSAHS as an important risk factor for the onset of AF, 
mainly due to the fact that its presence attenuates the effectiveness of the antiarrhythmic treatment used in patients with AF. For this reason, the early detection of OSAHS can improve the management and prognosis of patients using medication for the treatment of AF [13].

In addition, in the present report, the patient did not improve his clinical condition with drug treatment. According to the Brazilian Guidelines for Atrial Fibrillation, the limited efficacy of antiarrhythmic drugs for maintaining sinus rhythm, associated with the toxicity of these drugs, stimulated the development of non-pharmacological therapeutic techniques for the prevention and control of $\mathrm{AF}$ [14]. The ablation technique was therefore chosen as the best alternative for this patient.

A catheter ablation was performed on the patient, since a surgical ablation is riskier and more predisposed for the patient to develop complications. Surgical ablation of AF is a technique that has been developed over the years. The surgical approach to treat AF reliably and successfully was first developed and performed by James Cox in 1987, who devised the Maze procedure, which he perfected for several years, and its final iteration, the Cox procedure-Maze III, which consisted of a binaural procedure, sets of cut and seam injuries along with excision of the left atrial appendage (LAA). The technique Cox developed became later the standard for surgical treatment of AF. However, the technical complexity of this procedure, together with the risks associated with prolonged time in cardiopulmonary bypass, led to the development of simpler surgical techniques. These range from mini-thoracotomy or thoracoscopy, left atrial epicardial procedures to open biatrial endo-epicardial procedures [15].

The patient's procedure was carried out successfully and without complications. A study comparing ablation surgery and catheter ablation concluded that there are some limitations when trying to confirm conduction areas. Therefore, regardless of the set of lesions or the energy source, there are no reliable intraoperative tools to confirm electrical isolation or line conduction block, and gaps are a major recurrence factor for atrial arrhythmia after surgery. AF surgery is mainly an empirical procedure, the objective of which is to isolate the pulmonary veins and reduce the possibility of AF perpetuation by compartmentalizing the atria; however, surgical ablation brings more complications than benefits for the patient undergoing this procedure. Currently, catheter ablation is one of the most preferred procedures, since it indicates superiority when it comes to antiarrhythmic drugs achieving the absence of atrial arrhythmias. In addition to that, reducing the need for cardioversion and reducing hospitalizations related to cardiac events is beneficial [16].

After the recovery period, the patient was discharged with treatment of Xarelto ${ }^{\oplus}$ (rivaroxaban) - as a prevention of thrombotic event-and Peprazol ${ }^{\oplus}$ (omeprazole), for use for 30 days. Oral anticoagulation in high-risk patients with AF includes vitamin $\mathrm{K}$ antagonists or more recent anticoagulants, such as thrombin inhibitors Pradaxa $^{\circledR}$ (dabigatran etexilate), in addition to factor Xa inhibitors 
$\left(\right.$ Xarelto $^{\oplus}$, Eliquis $\left.{ }^{\oplus}\right)$ [13]. The anticoagulation schedule does not include antiplatelet agents-such as Aspirin ${ }^{\oplus}$ (acetylsalicylic acid) and Plavix ${ }^{\oplus}$ (clopidogrel bisulfate), $\beta$-adrenergic blockers or calcium. Calcium channel blockers help in the rate of ventricular control, improve symptoms and have a low risk profile, but have low efficacy when it comes to reducing AF episodes [17].

Proton blocking drugs (Peprazol ${ }^{\circledR}$ or Pantozol $^{\circledR}$ ) have been recommended in high doses (40 mg twice a day), according to the Brazilian Guidelines for Atrial Fibrillation, after ablation for 30 days, to reduce acid reflux for the esophagus, regardless of the findings of monitoring esophageal temperature during the procedure [14]. Oral contrast-enhanced chest tomography to investigate possible fistula formation can also be performed [18].

A study proposal would be through the analysis of the complications developed in a comparative study of patients who have a diagnosis of atrial fibrillation and who are under continuous treatment with antiarrhythmics or have undergone through cardioversion. In addition to that, patients who performed catheter ablation to verify which treatment would be the most appropriate would be another topic for research. A comparative efficacy study could also be performed between surgery and catheter ablation in patients [19].

The present report presents the history of an elderly patient who arrived at the hospital's ED with irregular heart rhythm and palpitations. The patient's symptoms, associated with the ECG results, indicated paroxysmal AF. Electrical cardioversion was performed, and after, cardiac ablation via the femoral vein at the hospital's cardiology service. There were no complications during the procedure. As a routine imaging exam after ablation, control esophagogastroduodenoscopy was requested, which did not show the formation of atrio-esophageal fistula; and the electrocardiogram, which showed normal sinus rhythm. The patient remained in the cardiac ICU for observation for 24 hours. After the electrical cardioversion and catheter ablation procedures, the patient improved his clinical picture of AF and was discharged after 24 hours of hospitalization. He received treatment to perform at home to reduce acid reflux into the esophagus and to prevent thrombosis. It is concluded that, after the procedures of electrical cardioversion and catheter ablation, the patient presented improvement of the clinical picture of AF. According to the patient's follow-up, he also did not present pulmonary thromboembolism after hospital discharge. It is believed, therefore, that this form of treatment and management of paroxysmal AF is effective in solving the proposed problem and can also serve as a reference for other professionals in the cardiology and cardiac ICU service.

\section{Acknowledgements}

This study was funded in part by the Coordination of Improvement of Higher Level Personnel-Brazil (CAPES)—Finance Code 001 by the National Council of Scientific and Technological Development-Brazil (CNPq)-Doctorate GD and by Research Foundation of the State of Rio Grande do Sul (FAPERGS). 


\section{Conflicts of Interest}

Authors declare not having any conflict of interest regarding this article.

\section{References}

[1] Cuculich, P. and Kates, A. (2014) Manual Washington de especialidades clínicas-Cardiología. 3a edicion, Wolters Kluwer Pvt Ltd., Barcelona, España, 468.

[2] Go, A., Hylek, E. and Phillips, K. (2001) Prevalence of Diagnosed Atrial Fibrillation in Adults and National Implications for Rhythm Management and Stroke Prevention: The Anticoagulation and Risk Factors in Atrial Fibrillation (ATRIA) Study. The Journal of the American Medical Association, 285, 2370-2375.

https://jamanetwork.com/journals/jama/fullarticle/193807 https://doi.org/10.1001/jama.285.18.2370

[3] Calkins, H., Hindricks, G., Cappato, R., et al. (2017) 2017 HRS/EHRA/ECAS/ APHRS/SOLAECE Expert Consensus Statement on Catheter and Surgical Ablation of Atrial Fibrillation. Heart Rhythm, 14, 275-444.

https://www.ncbi.nlm.nih.gov/pubmed/28506916 https://doi.org/10.1016/j.hrthm.2017.05.012

[4] Hakalahti, A., Biancari, F., Nielsen, J.C., et al. (2015) Radiofrequency Ablation vs. Antiarrhythmic Drug Therapy as First Line Treatment of Symptomatic Atrial Fibrillation: Systematic Review and Meta-Analysis. Europace, 17, 370-378. https://www.ncbi.nlm.nih.gov/pubmed/25643988 https://doi.org/10.1093/europace/euu376

[5] Chugh, S., Blackshear, J., Shen, W., et al. (2001) Epidemiology and Natural History of Atrial Fibrillation: Clinical Implications. Journal of the American College of Cardiology, 37, 371-378. https://www.ncbi.nlm.nih.gov/pubmed/11216949 https://doi.org/10.1016/S0735-1097(00)01107-4

[6] Fukui, A., Tanino, T., Yamaguchi, T., et al. (2020) Catheter Ablation of Atrial Fibrillation Reduces Heart Failure Rehospitalization in Patients with Heart Failure with Preserved Ejection Fraction. Journal of Cardiovascular Electrophysiology, 31, 682-688. https://www.ncbi.nlm.nih.gov/pubmed/31985099 https://doi.org/10.1111/jce.14369

[7] Friberg, L. and Bergfeldt, L. (2013) Atrial Fibrillation Prevalence Revisited. Journal of Internal Medicine, 274, 461-468.

https://www.ncbi.nlm.nih.gov/pubmed/23879838 https://doi.org/10.1111/joim.12114

[8] Capucci, A. and Compagnucci, P. (2020) Is Delayed Cardioversion the Better Approach in Recent-Onset Atrial Fibrillation? No. International Journal of Internal and Emergency Medicine, 15, 5-7. https://www.ncbi.nlm.nih.gov/pubmed/31721018 https://doi.org/10.1007/s11739-019-02224-y

[9] Odozynski, G., Dal Forno, A., Lewandowski, A., et al. (2018) Ablação de fibrilação atrial paroxística em mulheres: Compreendendo a diferença entre os gêneros. $A r-$ quivos Brasileiros de Cardiologia, 110, 55-57.

http://www.scielo.br/scielo.php?script=sci_arttext\&pid=S0066-782X2018000500449 \&lng=pt\&nrm=iso\&tlng=pt

[10] January, C., Wann, L., Alpert, J., et al. (2014) 2014 AHA/ACC/HRS Guideline for the Management of Patients with Atrial Fibrillation: A Report of the American College of Cardiology/American Heart Association Task Force on Practice Guidelines and the Heart Rhythm Society. Journal of the American Heart Association, 130, 199-267. https://www.ahajournals.org/doi/full/10.1161/CIR.0000000000000041 
https://doi.org/10.1161/CIR.0000000000000041

[11] Loungani, R., Rehorn, M., Geurink, K., et al. (2020) Outcomes Following Cardioversion for Patients with Cardiac Amyloidosis and Atrial Fibrillation or Atrial Flutter. American Heart Journal, 222, 26-29.

https://www.ncbi.nlm.nih.gov/pubmed/32004797

https://doi.org/10.1016/j.ahj.2020.01.002

[12] Rodrigues, T. and Miranda, R. (1999) Epidemiology, Etiology and Classification of Atrial Fibrillation. Journal of Cardiac Arrhythmias, 12, 4-11.

http://relampa.org.br/details/263/pt-BR/aspectos-epidemiologicos--etiologia-e-class ificacao-da-fibrilacao-atrial

[13] Huang, B., Liu, H., Scherlag, B., et al. (2020) Atrial Fibrillation in Obstructive Sleep Apnea: Neural Mechanisms and Emerging Therapies. Trends in Cardiovascular Medicine, 5. https://www.ncbi.nlm.nih.gov/pubmed/32008837

https://doi.org/10.1016/j.tcm.2020.01.006

[14] Magalhães, L., Figueiredo, M., Cintra, F., et al. (2016) II Diretrizes Brasileiras de Fibrilação Atrial. Arquivos Brasileiros de Cardiologia, 106, 141-197.

http://www.scielo.br/scielo.php?script=sci_arttext\&pid=S0066-782X2016003100001 https://doi.org/10.5935/abc.20160055

[15] Cox, J., Schuessler, R., Lappas, D., et al. (1996) An 81k-Year Clinical Experience with Surgery for Atrial Fibrillation. Annals of Surgery, 224, 267-273.

https://www.ncbi.nlm.nih.gov/pubmed/8813255 https://doi.org/10.1097/00000658-199609000-00003

[16] Anannab, A., Gianni, C., Della Rocca, D., et al. (2020) Catheter Ablation Is Preferred over Surgery for Persistent Atrial Fibrillation. Journal of Cardiovascular Electrophysiology, 31, 24-29. https://www.ncbi.nlm.nih.gov/pubmed/32293063 https://doi.org/10.1111/jce.14497

[17] Miura, K., Ikemura, N., Kohsaka, S., et al. (2020) Treatment Strategies and Subsequent Changes in the Patient-Reported Quality-of-Life among Elderly Patients with Atrial Fibrillation. American Heart Journal, 222, 83-92.

https://www.ncbi.nlm.nih.gov/pubmed/32028139 https://doi.org/10.1016/j.ahj.2020.01.011

[18] Da Silva, R., Arantes, R., Araújo, L., et al. (2018) Incidence of Esophageal Lesions in Patients Undergoing Ablation for Atrial Fibrillation with Multipolar Pulmonary Vein Ablation Catheter (PVAC-GOLDr). Journal of Cardiac Arrhythmias, 31, 71-79.

http://www.relampa.org.br/details/1116/pt-BR/incidencia-de-lesoes-esofagicas-em-pa cientes-submetidos-a-ablacao-de-fibrilacao-atrial-com-cateter-circular-multipolar-pvac-goldrhttps://doi.org/10.24207/1983-5558v31.2-004

[19] Kheiri, B., Barbarawi, M., Zayed, Y., et al. (2019) Antiarrhythmic Drugs or Catheter Ablation in the Management of Ventricular Tachyarrhythmias in Patients With Implantable Cardioverter-Defibrillators. Circulation: Arrhythmia and Electrophysiology-American Heart Association, 12, 41-46.

https://www.ncbi.nlm.nih.gov/pubmed/31698933

https://doi.org/10.1161/CIRCEP.119.007600 